\title{
Combs Prognostic Index
}

National Cancer Institute

\section{Source}

National Cancer Institute. Combs Prognostic Index. NCI Thesaurus. Code C127861.

A prognostic index developed to predict the outcome of reirradiation for recurrent

glioma. The index accounts for histology, patient age, and time between initial radiation and re-irradiation. 